\title{
Para um descentramento do usuário no design: uma abordagem pós-estruturalista
}

\section{For a decentration of the user in design: a post-structuralist approach}

\author{
Felipe Machado de Souza, Universidade Federal de Santa Catarina. \\ mazafelipe@gmail.com
}

\author{
Mériti de Souza, Universidade Federal de Santa Catarina. \\ meritisouza@yahoo.com.br
}

Francisco Antonio Pereira Fialho, Universidade Federal de Santa Catarina.

fapfialho@gmail.com

\begin{abstract}
Resumo
No design modernista, bem como em discursos contemporâneos como o Design Centrado no Usuário, prevalecem modelos projetuais que concebem o uso dos artefatos a partir de uma perspectiva universal que parecem supor o sujeito definido a priori. No artigo, exploramos uma proposta pós-estruturalista no design como possibilidade de reconhecer que um objeto pode adquirir usos e significados singulares, indo além do que foi pensado como único e universal para ele pelo projetista. Cada usuário pode utilizar um mesmo objeto singularmente, deslocando a ideia de um uso único, que é dado como certo na base moderna de produção. Por meio de análises de fotografias e cartas de usuários, uma equipe de designers propôs soluções para resolver as situações relatadas nesses suportes. A partir de uma técnica criativa, os profissionais sugeriram soluções projetuais para os relatos subjetivos analisados. Verificou-se que a transformação singular dos artefatos por parte dos usuários revela outras concepções inicialmente não consideradas nos projetos.
\end{abstract}

Palavras-chave: Pós-estruturalismo, Sujeito, Subjetividade, Método, Metodologia

\begin{abstract}
In modernist design, as well as in contemporary discourses such as User-Centered Design, design models prevail that conceive the use of artifacts from a universal perspective that seem to assume the subject defined a priori. In the article, we explored a post-structuralist proposal in design as a possibility to recognize that an object can acquire unique uses and meanings, going beyond what was thought as unique and universal for him by the designer. Each user can use the same object singularly, shifting the idea of a single use, which is taken for granted in the modern production base. Through analysis of photographs and letters from users, a team of designers proposed solutions to solve the situations reported on these supports. Using a creative technique, the professionals suggested design solutions for the subjective reports analyzed. It was found that the unique transformation of the artifacts by the users reveals other conceptions not initially considered in the projects.
\end{abstract}

Keywords: Post-structuralism, Subject, Subjectivity, Method, Methodology 


\section{Introdução}

A palavra design, na situação de verbo - to design -, significa, entre outras coisas, "projetar", "simular" e "proceder de modo estratégico" (FLUSSER, 2007, p. 181). De acordo com Eguchi (2012), para Flusser, design não é uma tradução de Gestaltung (configuração), como passou a aparecer inicialmente nos textos da HfG (Escola Superior da Forma), vertidos para o inglês, mas, sim, o processo por meio do qual se cria o mundo artificial: o processo de "designação". Portanto, "design é o projeto inerente a qualquer atividade de criação" (EGUCHI, 2012, p. 17).

Para Ferroni (2010) projetar é a possibilidade de transformar qualquer proposta abstrata em concreta e, ao mesmo tempo, atividade criativa desenvolvida graças ao auxílio de um método. $\mathrm{O}$ projeto é o veículo que transporta um conceito à realidade e, simultaneamente, é uma ideia ligada ao que está por vir (BROWN, 2010; MARTINS \& LINDEN, 2012).

Martins e Linden (2012, p. 105) explicam que o projeto no design

é uma atividade que ocorre no tempo e que utiliza técnicas para gerar e avaliar ideias que necessite de uma abordagem criativa. Se não é necessário algo novo (inovador, criativo), não é um problema de Design. Se não é temporal e/ou não utiliza técnicas (conhecimento sistematizado), não é um projeto. Isso não quer dizer que um designer não possa resolver um problema que não seja criativo, ou não possa trabalhar sem o uso de técnicas, ou não possa dar uma ideia na hora em que o problema é apresentado; apenas em qualquer desses casos não estará fazendo um projeto.

$\mathrm{Na}$ área projetual do design foram propostos diversos discursos metodológicos para o desenvolvimento de artefatos. Muitos são reconhecidos e utilizados até os dias de hoje como os de Bonsiepe (1984), Baxter (1998), Löbach (2000), Munari (2008) etc. Mas, cada vez mais, tornase necessário evoluir os métodos "em relação à complexidade que caracteriza a vida" (MARTINS \& LINDEN, 2012, p. 99). Não é possível manter o ensino da metodologia projetual no design preso, exclusivamente, aos modelos clássicos. Esses modelos são centrados em concepções universais sobre o sujeito e sobre o conhecimento, negligenciando concepções singulares. Assim, suas estratégias de produção do conhecimento não são capazes de incorporar, com profundidade, as dimensões subjetivas dos usuários.

Diversos autores vêm buscando melhor compreender os métodos de projetação no design, procurando formular estratégias que incorporem as subjetividades (MORAES, 2010; KASPER, 2009). Uma das possibilidades é explorar o campo do design a partir das chamadas Ciências Humanas. Isso porque, o design, pelo menos o ensinado no Brasil, é predominantemente pragmático, proveniente das escolas alemã e americana, portanto, "pensado mais em termos de causa, efeito e eficiência do que reflexão e autorreflexão" (EGUCHI, 2012, p. 11).

Problematizamos o design como atravessado por concepções modernas de sujeito e de conhecimento que acompanham as referências hegemônicas que sustentam a exclusividade do universal e subsidiam a modalidade de conhecimento denominada ciência. Apresentamos alguns aspectos das teorias pós-estruturalistas que questionam a universalidade e qualificam a subjetividade e o singular. Por fim, analisamos o entrelace do design com as concepções pósestruturalistas, ampliando as possibilidades de trabalho do designer sobre o objeto e o usuário.

Para atingir nossos objetivos apresentamos uma pesquisa aplicada e de abordagem qualitativa. Por meio de análises de fotografias e cartas de usuários, designers de uma empresa de 
eletrodomésticos propuseram soluções para resolver algumas necessidades que podem extrapolar o projeto. Recorremos a uma investigação dos problemas mencionados nos relatos subjetivados sobre o uso de um refrigerador, e os designers exploraram soluções projetuais para tal eletrodoméstico.

Entendemos que é necessário discutir métodos que articulem o singular e o universal na execução de projetos, relevando o aspecto criativo e inovador do usuário que tende a produzir novos usos para os objetos, para além daqueles previstos pelo projetista.

\section{A universalidade dos projetos do design}

A prática projetual do design nasceu em paralelo a revolução industrial, quando se começa a "ampliar uma noção comum de projeto a áreas tão dispares como a tipografia, a arquitetura ou a moda. Até então, projetar um livro, uma casa ou uma peça de roupa eram saberes distintos, isolados disciplinarmente" (MOURA, 2018, p. 39). Contudo, muitos atribuem a origem do design como disciplina junto ao aparecimento do movimento e escola da Bauhaus (MOZOTA, 2011).

Fundada com um forte viés racionalista e funcionalista, grande parte da Bauhaus sugeria que os objetos de nosso entorno deveriam ser determinados por suas funções prático-funcionais, devendo ser pensados pela simplicidade utilitária (LÖBACH, 2000; CARDOSO, 2001). "O design da Bauhaus tinha como meta a perfeição estética, induzida por uma total confiança no funcionalismo e desconfiança de distorções introduzidas pela psique humana na concepção de um objeto de design" (MOZOTA, 2011, p. 37). Logo, incorporou-se às práticas do design determinadas disciplinas científicas, promovendo um verdadeiro processo de aproximação das pesquisas da área com a ciência e, consequentemente, afastando-a da raiz artística que predominava no design praticado anteriormente a Bauhaus (MARTINS \& LINDEN, 2012).

A Bauhaus concentrava-se na materialidade e na ideologia de tradição positivista, proveniente das áreas das exatas e das engenharias, abandonando dimensões subjetivas nos projetos (BONSIEPE, 2011). Segundo Bonsiepe (2011), por ter base nessas áreas, o design desenvolveuse a partir de métodos projetuais centrados em concepções racionais e universais. Desse modo, "buscava impor tipos e padrões industriais baseados em um suposto racionalismo científico" (CARDOSO, 2001, p. 115). Tais esforços são produtos das tentativas do século XIX de racionalizar áreas da investigação humanística, cujas metodologias são em grande parte descritivas e subjetivas, qualificáveis em vez de quantificáveis (MOURA, 2018).

Mais tarde, ainda sob forte influência do pensamento racional, a década de 1960 deu ao design, pela primeira vez, reconhecimento substancial acadêmico. Esse período foi promissor para as pesquisas de projeto em design. A conferência de 62 foi um símbolo no lançamento da metodologia do design como disciplina ou campo de estudo (MARTINS \& LINDEN, 2012). O conhecimento científico deu bastante fomento à área e também à formação do designer. De acordo com Najar (2019, p. 150), nesse período, para legitimar-se, "o design incorpora em seus processos os padrões da indústria, adequados ao aumento do consumo e à necessidade de produção em massa, além de adaptar-se a rígidos padrões positivistas de pesquisa e inferência". 
Os modelos de pesquisa de design passam a considerar como conhecimento confiável apenas aquilo que pode ser observado, mensurado e isolado de qualquer subjetividade. Ainda que o design não tenha aderido hegemonicamente a um mesmo modelo - e a própria ciência da época já produzisse críticas ao positivismo - este se firmou como paradigma predominante na área (NAJAR, 2019, p. 150).

Os métodos em design tornaram-se cada vez mais rígidos ao deslocarem progressivamente $\mathrm{o}$ foco dos seres humanos para a discussão do processo (meios). Houve uma progressiva tecnocratização das pesquisas, deixando de lado os sujeitos (MARTINS \& LINDEN, 2012).

Naquele tempo, o debate sobre metodologia ocupou um lugar privilegiado porque se acreditava que os métodos projetuais poderiam criar uma ponte entre design e ciências, contribuindo para estruturar o processo projetual, tornando mais objetivo e livrando-o das veleidades subjetivas (BONSIEPE, 2011, p. 226).

Para Moura (2018), encontramos nessa identidade inicial do design, uma pretensão universal: unificar práticas distintas através da ideia de projeto; alcançar um design universal, neutro e intemporal, por meio da racionalização, cumpria funções importantes para a identidade do design que se construía. De certa maneira, prometia uma economia metodológica e garantia usar o mesmo processo em todos os contextos e épocas (CARDOSO, 2001). Acreditava-se que as objetivações e universalizações das atividades criativas do design conduziam-no a resultados originais e perfeitos (MOURA, 2018).

O que sustentava essas concepções era a crença na objetividade da razão, que pode ser entendida como uma leitura sobre a constituição subjetiva reduzida a capacidade cognoscente que tornaria o ser humano capaz de conhecer o real e de tomar decisões racionais e éticas. Essa leitura, típica do estruturalismo, acompanha a tradição hegemônica ocidental sobre o sujeito e sobre o conhecimento denominado ciência. Nesse sentido, conforme explica Kasper (2009 p. 20), o design via o uso "segundo o modelo da tarefa, e a fazer do usuário o mero executante desta", supondo entidades definidas a priori (sujeitos, objetos, necessidades, funções etc.) e, sobretudo, estáveis, como se o usuário fosse no máximo aprender, obedientemente, o uso correto do dispositivo (KASPER, 2009).

A racionalidade sustenta que o humano seria constituído por um atributo - a razão - capaz de oferecer ao sujeito a plena compreensão da realidade, de si e do outro. Assim, essa capacidade cognoscente de conhecimento seria objetiva, neutra, universal, não sendo atravessada por afetos, emoções, contextos econômicos, sociais, históricos, etc. A concepção da razão objetiva animava os métodos científicos hegemônicos - bem como, as propostas dos projetos de design - levando os adeptos dessa vertente a entender que ela traria os melhores resultados (CHAUI, 2000).

A concepção hegemônica sobre o sujeito moderno acompanha os pressupostos da consciência como conformada por uma razão e por uma objetividade plena que poderiam oferecer o acesso total a realidade e ao conhecimento do sujeito sobre si e sobre o mundo. Subjaz a essa concepção a ideia de que a consciência seria configurada pela intenção, o sujeito seria capaz de conhecer e definir a sua ação a partir da representação antecipada sobre a causa e o efeito, isto é, sobre seu ato e os resultados de tal ato. Ainda, na leitura sobre o sujeito moderno, predomina a ideia de que as subjetividades das pessoas seriam conformada da mesma forma: seriam reduzidas aos mesmos pressupostos e a idênticas formas de ser e de funcionar (PETERS, 2000). Essas leituras alimentam teorias nas mais diversas áreas e, no caso do design, emergem associadas a ideia de que ao definir 
o objeto, sua função e seu uso, os usuários representarão, compreenderão e utilizarão os artefatos similarmente.

Por décadas prevaleceu, em certos casos ainda prevalece, discursos projetuais objetivos, lineares, causais e universais, que apontam e pressupõem uma relação direta entre objeto e uso. "[E]sta pretensão de universalidade esconde sempre uma posição dominante, naturaliza um modo de ser e de praticar design que se torna prevalecente" (MOURA, 2018, p. 45). Segundo Moura (2018 p. 44), "essa crença numa universalidade positiva que impedem o design de lidar com situações que escapam a essa lógica".

Embora ultrapassadas há, ainda, como explica Kasper (2009, p. 20), doutrinas recentes na área que "[c]olocam o usuário no centro das preocupações do designer: design centrado no usuário, usabilidade, design universal, etc." Essas metodologias, em sua maioria, consideram o usuário como portador de necessidades específicas e orientam o projeto, cujo esforço visa otimizar a relação - predefinida - com o artefato. "O designer coloca-se, como nos melhores dias do funcionalismo, em posição de controlar o usuário, às vezes até a obsessão" (KASPER, 2009, p. 20).

\begin{abstract}
O processo de desenvolvimento da experiência do usuário consiste em assegurar que nenhum aspecto da experiência do usuário acontecerá sem intenção consciente, explícita. Isso significa considerar todas as possibilidades de ação que o usuário pode tomar e entender sua expectativa de cada etapa do processo (KASPER, 2009, p. 20).
\end{abstract}

\title{
Os processos de singularização
}

Segundo Peters (2000), o pós-estruturalismo questiona o racionalismo e a tendência totalizante que o estruturalismo havia retomado do positivismo, colocando em dúvida, além disso, a pretensão de identificar estruturas universais que seriam comuns a todas as culturas e à mente humana em geral. Para o autor, o estruturalismo possui base no conhecimento produzido por um eu racional e objetivo, um conhecimento capaz de fornecer verdades universais sobre o mundo e sobre o sujeito. Esse conhecimento poderia ser supostamente aplicado a todas as práticas e instituições humanas, sendo considerado a base última daquilo que é verdadeiro e, portanto, daquilo que é certo e daquilo que é bom.

O pós-estruturalismo efetua uma enérgica crítica aos pressupostos universalistas da racionalidade que estão subjacentes ao sujeito humanista (PETERS, 2000). Jacques Derrida (2002), filósofo que faz parte do movimento pós-estruturalista, questionava a "estruturalidade da estrutura" ou a ideia de "centro". O filósofo acreditava que era necessário o "descentramento" da estrutura, do significado transcendental e do sujeito soberano. $\mathrm{O}$ "descentramento do sujeito anunciado pelo pós-estruturalismo rompe com a concepção de um ser humano essencialista e universal compreendido pelos estruturalistas e permite pensar nas mais variadas formas de experiências vivenciadas em diferentes contextos, por diferentes indivíduos" (AGUILAR \& GONÇALVES, 2017, p. 38).

Para tanto, Derrida $(2001 ; 2004)$ utiliza a estratégia da desconstrução. Desconstruir significa questionar os pressupostos dos modos de subjetivar e de conhecer que ganharam hegemonia. $\mathrm{O}$ filósofo se refere aos pressupostos da substância; da identidade; da lógica formal, que recorrem a 
causa e ao efeito; do binarismo, que operam com pares de opostos; do universal que exclui o singular, etc. A desconstrução se refere a uma estratégia de produção do conhecimento que se propõe a localizar os pares de opostos que operam em um dado contexto que se deseja estudar e proceder a inversão desses pares, colocando no lugar do superior o que ocupará o lugar de inferior. Ainda, ato contínuo a esse movimento de inversão, a desconstrução propõe o deslocamento, ou seja, deslocar o significado atribuído a essa oposição estudada e oferecer novos sentidos a ela (DERRIDA, 2008).

Desconstruir é uma proposta pós-estruturalista que consiste, na inversão das dicotomias clássicas tais como sujeito/objeto; significante/significado; dentro/fora; corpo/mente; fala/escrita; presença/ausência; natureza/cultura; homem/mulher; forma/sentido etc., minando as correntes hierárquicas sustentadoras e estruturais do pensamento ocidental (CARDOZO, 2014). "Desconstruir a oposição significa, primeiramente, em um momento dado, inverter a hierarquia" (DERRIDA, 2001, p. 48). O sentido derridiano de desconstrução problematiza um sistema de pensamento universal e dominante que impera no ocidente (LANGARO, 2012).

Entender que a subjetividade é constituída tanto pelo universal quanto pelo singular, significa entender que o universal (que diz respeito a rede social, econômica, cultural, linguística) faz parte da constituição do sujeito, da mesma forma que o singular (que diz respeito a apropriação que cada pessoa faz do universal). Assim, temos aqui um sujeito descentrado, no sentido de que não existe uma linearidade, continuidade, identidade, razão, que garantiriam uma consciência una e plenamente acessível ao sujeito. O sujeito é de forma concomitante razão e emoção; natureza e cultura; consciência e inconsciente, e se equilibra na interface entre esses aspectos. Esses binarismo e hierarquias são descontruídos (DERRIDA, 2008, 2001).

É cada vez mais necessário desconstruir os métodos do design que são elaborados segundo concepções de sujeito e de conhecimento que predominam no ocidente. Assim, passamos a problematizar alguns pressupostos dos ditos métodos tradicionais do design: 1) a crença na possibilidade de captar uma intencionalidade última e universal do uso e do significado dos objetos; 2) o senso de causalidade e linearidade do projeto.

No design, a corrente desconstrutivista surgiu para demonstrar como alguns elementos projetuais eram dados como corretos e garantidos, sem que houvesse reflexão sobre possíveis alternativas (EGUCHI, 2012 p. 20). Podemos pensar a desconstrução no design como uma possibilidade de reconhecer que um mesmo objeto pode adquirir múltiplos significados, apontando também para o que é deixado de fora da intenção do projetista. Um produto pode apresentar leituras tão diversificadas que ele perderia o significado intencional para o qual foi concebido. Cada usuário pode utilizar de maneira diferente um mesmo objeto, extrapolando e deslocando o significado último e universal, que é dado como certo na base ideológica da produção, e que trabalha com a concepção exclusiva do sujeito universal. "Desconstruir um objeto não é destruir o seu significado, nem afirmar que o significado não existe, mas é reconhecer o ausente, o que foi deixado de fora. Quer tenha sido conscientemente intencional, ou não." (EGUCHI, 2012, p. 27).

Reconhecer as diferenças presentes em cada usuário implica reconhecer múltiplos usos, produzindo multiplicidades nos objetos. É preciso sobrepor o que é imposto ao designer (de que 
o uso é algo que pode ser controlado) ou, como explana Kasper (2009), prescrito. Os usos podem não se reduzir àquilo que foi prescrito pelo projeto, pelo contrário, os usuários possuem necessidades singulares capazes de desviar os usos, propondo verdadeiras inovações (KASPER, 2009). Portanto, é necessário rever a ideia de que o designer projeta em termos de causa e efeito e de uma intencionalidade última de uso.

Inverter a lógica hegemônica, binária e universal do design tradicional, é deslocar o significado único atribuído ao objeto problematizando a ideia de um suposto sujeito universal. Desconstruir é colocar o usuário singular como agente do projeto, tornando possível reconhecer a presença da singularidade nas subjetividades, observando as multiplicidades de usos e de significados dos artefatos. As subjetividades dos sujeitos-usuários extrapolam essa suposta ilusão que pressupõe tanto a concepção do usuário como exclusivamente racional e universal quanto a relação direta entre uso, objeto e intenção.

Nota-se que existe um entendimento de causalidade e intencionalidade que perpassa o design: o designer pode assegurar, aos usuários, os resultados das experiências e dos usos de produtos, interfaces, sistemas etc.

[...] o DCU [Design Centrado no Usuário] é uma forma em que se coloca o usuário no centro do processo para o desenvolvimento de produtos interativos onde são consideradas as características, necessidades e desejos das pessoas que efetivamente usarão tais produtos. Todas as experiências que o usuário tem enquanto utiliza uma interface deveriam ser o resultado de uma decisão do designer, [...] o design centrado no usuário é um processo que assegura que estas experiências não sejam frutos do acaso ou de acidentes... (ARAÚJO et al., 2017, s.p).

Logo, suprime-se as subjetividades, que se referem a atitude parcial e pessoal, ditada por sentimentos variados (CHAUI, 2000). Segundo Chaui (2000) o Eu, pessoa e sujeito constituem a consciência como subjetividade, portanto o usuário é um ser dotado de subjetividade. Sendo ela um processo de constituição do psiquismo com base no universal (das produções da humanidade), no particular (determinadas condições de vida) e no singular (que constituem indivíduos únicos), mesmo quando compartilham a mesma particularidade (SILVA, 2009).

Não pretendemos fazer uma crítica ao DCU, mas problematizar pressupostos dos métodos tradicionais do design e dos discursos que adotam a concepção da subjetividade como restrita a consciência entendida como pura intenção e razão, capaz de captar usos, significados e experiências a partir de uma única leitura sobre o sujeito. As subjetividades sendo universais e singulares não são restritas a uma modalidade única de consciência e de sujeito, sendo atravessadas por várias intencionalidades, o que escapa aos projetistas de design. Afinal, os usuários se apropriam e fazem diversos usos, para além daqueles pensados pelo designer. $\mathrm{O}$ objetivo não é propor um abandono do universal, mas demonstrar que junto a ele devem ser consideradas outras possibilidades como o uso singular que os usuários produzem e, como essa concepção pode auxiliar os projetistas a pensar soluções antes não contempladas para o uso dos objetos.

Não se trata de centralizar o usuário, universalizando-o em um modelo único que se repete ad infinitum, como propõe o DCU, mas, produzir um descentramento do usuário, entendendo-o como múltiplo e, a partir dessa leitura, subverter a ideia de projeto. Ao invés de pensar o usuário universal, passivo, centralizado, à espera da ação do designer, propomos pensá-lo como múltiplo, 
ativo, produtor, excluindo o binarismo que separa designer e usuário e, se aproximar da proposição de Derrida que entrelaça "o dentro e o fora". Ou seja, o filósofo propõe "o dentro $\times$ o fora", num sinal de apagamento dos binarismos, em que o fora é dentro, e nunca fora e/ou dentro (LANGARO, 2012). Isso porque, como explica, Heskett (2008), o significado do design é criado no encontro de designer e usuário.

Propomos olhar as práticas e lógicas de uso dos objetos no contexto em que acontecem, singularizadas pelos sujeitos. Isto não significa pensar que conseguiríamos imaginar como funcionaria a extrema variedade das singularidades perante um objeto mas, procurar imaginar a ampliação dos usos e da relação estabelecida pelos usuários com os objetos, para além de uma única definição estabelecida a priori. Como explica Wanderley (2013), as intervenções dos usuários subvertem as finalidades dos objetos aos quais foram inicialmente planejados e produzidos, provocando inovações.

\section{Procedimentos metodológicos}

Com o intuito de ilustrar as discussões anteriores, propusemos uma prática a equipe de designers de uma empresa multinacional de eletrodomésticos. O objetivo da atividade foi demonstrar a esses designers, habituados a projetar pelo viés tradicional, novas possibilidades de pensar produtos a partir de usos singulares, provenientes de usuários comuns.

A prática foi realizada em um workshop. A atividade ocorreu em agosto de 2019, sendo realizada na sede da empresa. Participaram 20 designers como, também, os coordenadores e diretor da área. Objetivou-se apresentar um ponto de vista mais antropológico do design no que tange a experiência de uso dos artefatos. Inicialmente, no workshop, discorreu-se sobre as principais diferenças entre o dito métodos tradicionais e métodos contemporâneos que confluem com perspectivas mais psicológicas e subjetivas.

Retratado o conteúdo inicial, discutiu-se a capacidade de subversão singular que os usuários fazem dos artefatos cotidianos. Demonstramos que os produtos podem sofrer apropriações, transformações ou ressignificações que não são, comumente, contempladas nas etapas de projetação. Um eletrodoméstico, por exemplo, pode ser usado de uma maneira que escape àquilo que seria considerada a sua finalidade e lógica original, a intencionalidade última de uso.

Para elucidar esse fato à equipe de designers, propusemos uma leitura de cartas elaboradas, individualmente, por nove usuários. Cada um desses tratou sobre a relação de uso com a sua geladeira, expondo, em forma de narrativa textual, fatores positivos e negativos dessa relação. Além da carta, os usuários disponibilizaram fotografias dos seus refrigeradores. Orientamos para os usuários-participantes que a carta para a geladeira poderia ser elaborada da mesma forma que se elabora uma carta para pessoas conhecidas, iniciando, por exemplo, com "Querida geladeira...". Essas cartas foram escritas por esses às suas geladeiras, de modo que obtivêssemos um sentido subjetivo do eletrodoméstico.

No tocante a perspectiva subjetiva a carta é um instrumento de pesquisa potente já que "o ato de escrever uma carta permite ao escritor tomar distância para uma reflexão, retomar uma frase antes de lançá-la ao destinatário, reler o texto para melhor compreender seu significado e 
normalmente expressar muita emoção e sentimentos que ficam registrados por tempo indeterminado" (NETTO et al., 2012, p. 15). Foram as emoções subentendidas nas cartas que propusemos à equipe de designers observar e analisar. Isso porque, de acordo com Silva (2004), a leitura de uma carta pelo outro possibilita uma troca de interpretações permitindo o confronto das significações de valores. Tal confronto de ideias pode ampliar, modelar, ressignificar as próprias representações valendo-se do diálogo com o outro.

Solicitou-se, então, aos designers que no decorrer da leitura das cartas e nas análises das fotografias, anotassem as questões que mais sobressaíram aos seus olhos, isto é, que ressignificassem e ampliassem o modo de ver o objeto. Para, posteriormente, dar continuidade a atividade proposta.
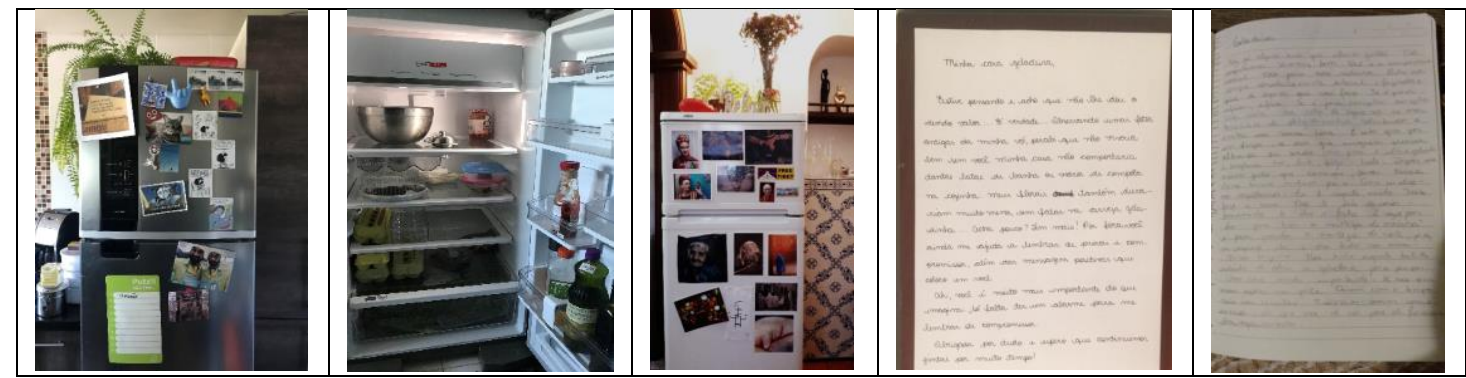

Figura 1: Exemplos de cartas e fotos enviadas pelos usuários

Após todos as cartas lidas e as fotografias analisadas, propusemos aos designers um exercício no qual desenvolvessem ideias e/ou soluções para os problemas relatados pelos usuários. Para a geração de ideias utilizou-se a Crazy Eights, técnica comumente utilizada no processo de ideação no design e tem como objetivo gerar um grande número de ideias em um tempo reduzido. De acordo com Correa et al. (2018), a Crazy Eights gera uma ampla variedade de soluções para um desafio específico. Ela tem como finalidade produzir, individualmente, oito ideias em oito minutos (uma por minuto), buscando resolver um problema ou encontrar possíveis soluções.

\section{Discussão dos resultados}

A Crazy Eights possibilitou a equipe de designers pensar soluções para as lógicas e práticas de uso descritas nas cartas e/ou observadas nas fotografias. A atividade permitiu gerar insights considerando, na idealização de um refrigerador, as relações singulares entre os usuários e suas geladeiras.

A maior parte dos designers explorou, nas suas oito soluções possíveis, mais de um fator levantado nas cartas e/ou pelas fotografias. Alguns profissionais preferiram escrever, outros desenhar, possíveis ideias de projetos que solucionassem as ponderações feitas pelos usuários.

Articular-se-á trechos das cartas com alguns insights projetuais da equipe de designers. Embora seja possível sistematizar a discussão por diversos prismas, optou-se por utilizar somente a principal possibilidade de projeto, aquela que apareceu com maior frequência tanto nas cartas como, principalmente, nas soluções projetuais da equipe de designers. Tal análise refere-se ao uso da geladeira como mural de recados. 
Na maioria das fotos (Figura 2) e relatos ficou claro o uso da geladeira como um espaço para colocar lembretes, avisos e frases. A usuária Vitória, por exemplo, explana: “( $p$ )or fora você ainda me ajuda a lembrar de provas e compromissos, além das mensagens positivas que coloco em você”. Maria reforça tal prática: "(p)or fim, minha querida geladeira, só queria dizer o quão nossa relação foi maravilhosa e sempre me alegrava ao ler os bilhetes colocados em sua porta". Rafael, por sua vez, afirma que não vive "sem colocar bilhetes importantes ou as contas a pagar". Esses comunicados podem se tornar obsoletos já que, como explica Patrícia, as "(f)otografias e palavras que estão já aí penduradas faz tanto tempo que esqueci de olhar (sic)"; ou, como ela mesma reitera em outro trecho, "agora cheia de ímãs de viagem [...] e uma lista de compras desatualizada". Notamos que usar a geladeira como um espaço de lembretes e memórias, por meio de avisos, contas, frases, imãs de viagens, imãs de estabelecimentos e fotografias, é uma prática comum aos usuários das cartas. Entretanto, muitas vezes, essa prática pode ser esquecida - no sentido de não considerada - na fase de criação e projetação de um refrigerador, por exemplo. Ao pensar a intencionalidade última de uso desse eletrodoméstico, que seria o de manter e refrigerar os alimentos, desconsidera-se possíveis modos de singularização como os lembretes e avisos incorporados e anexados a superfície do objeto.

As histórias das geladeiras subvertidas a murais impactaram a equipe de designers, pois apareceram mais de 20 insigths, de pelo menos 8 deles, considerando a área externa do refrigerador como um lugar passível de receber diferentes informações. Dentre as ideias surgidas pode-se mencionar: 1) prancha de anotações no refrigerador; 2) porta retrato digital sincronizado com o álbum do celular; 3) agenda sincronizada com prestadores de serviços para lembrar das contas; 4) gravador de lembretes para deixar recados; 5) superfície lisa para escrever coisa e colar coisas; 6) material de quadro, espaço para pincel e apagador; 8) rebaixo na cabeceira (para colocar a caneta e o apagador); 7) Imã prendedor para fotos; 8) aplicativo para passar foto do celular para a geladeira; 9) suporte de etiqueta e caneta anexada na geladeira; e 10) com tecnologia de voz, lembrar o que é importante (escutar os comandos dos usuários e depois recordá-los); etc.

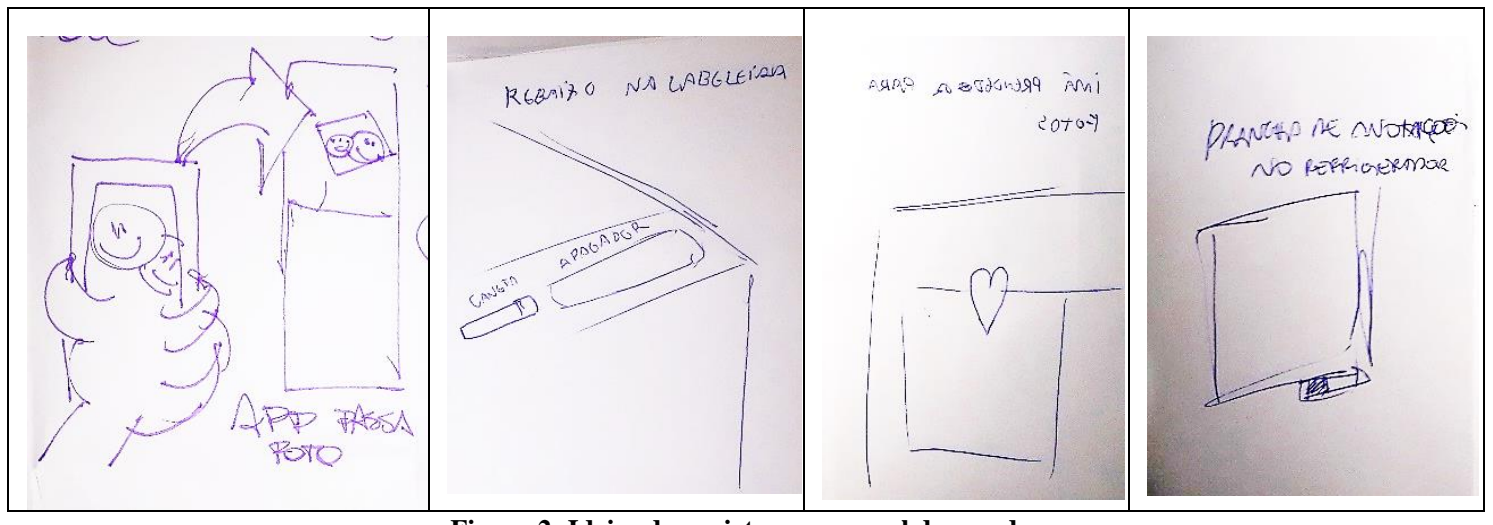

Figura 2: Ideias de projeto para mural de recados

Não objetivamos implementar as ideias surgidas ou de verificar sua viabilidade de projetação (em termos tecnológicos, materiais, custos etc.). A proposta e a discussão defendida é somente a de considerar o que é comumente refutado na elaboração dos projetos: as singularizações de uso. Apesar de muitas soluções da equipe de designers serem simples como, por exemplo, "escrever 
na porta" ou "prancha de anotações no refrigerador", elas cogitaram algo que antes não era intencionado no projeto. $\mathrm{O}$ fato de levar em conta a elaboração de um refrigerador com uma área específica para recados, com apagador e caneta integrada, já teria uma perspectiva inovadora no que tange a abordagem projetual que engloba os valores subjetivos analisados. Obviamente, as ideias que perpassam as novas mídias, como aplicativos de celular ou tecnologia de voz, necessitariam estudos aprofundados e maiores investimentos.

Apesar de terem aparecido, nas cartas, outras queixas dos usuários cujas soluções projetuais foram encontradas pela equipe de designers, discutiu-se somente um recorte daquilo que ocorreu na pesquisa aplicada. Além disso, é imprescindível esclarecer que a prática ocorreu em um curto período de tempo e que não se aprofundou a etapa de ideação, prototipagem, testes etc. $\mathrm{O}$ intuito principal foi demonstrar para a equipe de designers a importância de contemplar as singularidades nas abordagens projetuais e o quanto isso pode trazer insigths para os projetos. As cartas proporcionaram um novo olhar sobre a geladeira e os designers puderam se apropriar e repensar esse objeto a partir das singularidades dos usuários.

\section{Considerações finais}

Apresentamos de que modo ainda prevalecem projetos calcados nos modelos hegemônicos universais, que ainda atuam nas concepções dos artefatos, como o caso do Design Centrado no Usuário. Posteriormente, buscamos discutir situações projetuais que escapam a essa lógica tradicional. Discorremos de que maneira é possível (e necessário) considerar o modo como os usuários, por meio de intervenções criativas e singulares, repensam, transformam e subvertem as finalidades e intencionalidades de uso. Com isso, propomos um descentramento do usuário. Ao invés de considerar o usuário um executante obediente de um uso predefinido, um sujeito passivo, considerá-lo como um potencial projetista, que frequentemente desvia as intenções prescritas pelos designers.

É preciso explorar as formas singulares como os usuários transformam e expandem o modo de usar/conceber um artefato, sem abandonar, obviamente, o universal. Isso porque, embora não usem técnicas tampouco o conceito de projeto, usuários produzem inovação, que poderiam ser contempladas nas etapas projetuais. Portanto, é necessário (re)pensar metodologias que articulem o universal e o singular, descentralizando o sujeito, o objeto e o próprio designer.

\section{Referências}

AGUILAR, Adriana Brasil; GONÇALVES, Josiane Peres. Conhecendo a perspectiva pósestruturalista: breve percurso de sua história e propostas. Revista Conhecimento Online, Novo Hamburgo, a. 9, v. 1, p. 36-44, jan./jun. 2017.

ARAÚJO, Jéssica et al. O design centrado no usuário e a usabilidade: uma proposta de aplicativo para celular. In: CONGRESSO INTERNACIONAL DE ERGONOMIA E USABILIDADE DE INTERFACES HUMANO COMPUTADOR - USIHC, 16 2017. Florianópolis. Anais... Florianópolis, SC: Universidade Federal de Santa Catarina, 2017. s.p. 
BAXTER, Mike. Projeto de produto: guia prático para o design de novos produtos. São Paulo: Edgard Blücher, 1998.

BONSIEPE, Gui. Design, cultura e sociedade. São Paulo: Editora Blucher, 2011.

Editorial, 1984.

Metodologia experimental: Desenho Industrial. Brasília: CNPq/Coordenação

BROWN, Tim. Design thinking: uma metodologia poderosa para decretar o fim das velhas ideias. Rio de Janeiro: Elsevier, 2010.

CARDOSO, Rafael. Uma introdução à história do Design. São Paulo: Edgard Blücher, 2001.

CARDOZO, Guilherme Lima. O pós-estruturalismo e suas influências nas práticas educacionais: a pesquisa, o currículo e a "desconstrução". Pensares em Revista, Rio de Janeiro, n. 4, p. 118-134, jan./jul. 2014.

CHAUÍ, Marilena. Convite à filosofia. São Paulo: Ática, 2000.

CORREA, Lauriane et al. O Uso de Design Thinking no Apoio ao Desenvolvimento de Software: Um Estudo de Caso no Contexto de Academias de Musculação. Cardernos do IME - Série Informática, Rio de Janeiro, v. 41, p. 77-93, jan./dez. 2018.

DERRIDA, Jacques. Gramatologia. São Paulo: Perspectiva, 2004.

A Escritura e a Diferença. São Paulo: Perspectiva, 2002.

. Mal de Arquivo: uma impressão freudiana. Rio de Janeiro: Relume Dumará, 2001.

EGUCHI, Haroldo Coltri. Intencionalidade e indeterminação interpretativa no design de produto. 2012. 80 f. Dissertação (Mestrado em Design) - Programa de Pós-graduação em Design, Universidade Estadual Paulista Júlio de Mesquita Filho, Bauru, 2012.

FERRONI, Lucia. Da Bruno Munari all'epoca ditigale: nascita dell'idea di progetto, metodologie esemi concreti e natura virtuale del projeto in rete. Roma: Sapienza Universitá di Roma, 2010.

FLUSSER, Vilém. O mundo codificado: por uma filosofia do design e da comunicação. São Paulo: Cosac Naify, 2007.

HESKETT, John. Design. São Paulo: Editora Ática, 2008.

KASPER, Christian Pierre. Além da função, o uso. Arcos Design, Rio de Janeiro, v. 5, n. 2, p. 18-25. Jul./dez. 2009.

LANGARO, Fabíola. (Des)construções do masculino e do feminino na relação de mulheres-mães com fihos e filhas. 2012. 197 f. Dissertação (Mestrado em Psicologia) Programa de Pós-Graduação em Psicologia, Universidade Federal de Santa Catarina, Florianópolis, 2012.

MARTINS, Rosane Fonseca de Freitas; LINDEN, Júlio Carlos de Souza van der (Orgs.). Pelos caminhos do design: metodologia de projeto. Londrina: EDUEL, 2012.

LÖBACH, Bernard. Design Industrial: base para a configuração dos produtos industriais.

São Paulo: Edgard Blücher, 2000.

MORAES, Dijon de. Metaprojeto: o design do design. São Paulo: Blucher, 2010.

MOURA, Mário. O Design que o design não vê. Lisboa: Orfeu Negro, 2018.

MOZOTA, Brigitte Borja; KLÖPSCH, Cássia; COSTA, Felipe C. Xavier da. Gestão de Design: usando o design para construir valor de marca e inovação corporativa. Porto Alegre: Bookman, 2011.

MUNARI, Bruno. Das coisas nascem coisas. 2 ed. São Paulo: Martins Fontes, 2008. 
NAJAR, Rodrigo. Perspectivas epistemológicas e design: uma abordagem pós-estruturalista. Estudos em Design | Revista (online), Rio de Janeiro, v. 27, n. 1, p. 149-160, jan./abr. 2019.

NETTO, Carla; SPAGNOLO, Carla; FLORENTINO, José, Florentino; AMARAL, Lisandra; ZANCAN, Silvana, PORTAL, Leda Franciosi. Cartas: um instrumento desvelador que faz a diferença no processo educacional. Revista Educação por Escrito, Porto Alegre, v. 3, n. 1, p. 14-25, jul./dez. 2012.

PETERS, Michael. Pós-estruturalismo e filosofia da diferença. Belo Horizonte: Autêntica, 2000.

SILVA, Flávia Gonçalves. Subjetividade, individualidade, personalidade e identidade: concepções a partir da psicologia histórico-cultural. Psicologia da Educação, São Paulo, v. 28, n. 1, p. 169-195, jan./jun. 2009.

SILVA, Maria Emilia Lins e. "Cara professora": as práticas de escrita de um grupo de docentes. 2004. 277 f. Tese (Doutorado em Educação) - Programa de Pós-Graduação em Educação, Universidade Federal de Minas Gerais, Belo Horizonte, 2004.

WANDERLEY, Ingrid. O design dos outros: interações criativas na produção contemporânea dos artefatos. 2013. 180 f. Tese (Doutorado - Áre de Concentração: Design e Arquitetura) - Faculdade de Arquitetura e Urbanizmo, Universidade de São Paulo, São Paulo, 2013.

\section{Sobre o autor}

\section{Felipe Machado de Souza}

Doutorando do Programa de Pós-Graduação em Design, UFSC. Mestre em Design, pelo mesmo programa e instituição. Possui especialização em Psicologia Analítica, PUCPR; e em Antropologia Cultural, PUCPR. Graduado em Design Gráfico, UTFPR.

\section{Mériti de Souza}

Professora Permanente no Programa de Pós-Graduação em Psicologia, UFSC. Graduada em Psicologia, Unesp. Mestra em Educação, UNICAMP. Doutora em Psicologia (Psicologia Clínica), PUC-SP. Pós-Doutora em Psicologia pelo CES - Centro de Estudos Sociais - da Universidade de Coimbra e Pós-Doutora em Educação pela Unesp.

\section{Francisco Antonio Pereira Fialho}

Professor Titular no Programa de Pós-Graduação em Design, UFSC; e no Programa de Engenharia e Gestão do Conhecimento, UFSC. Graduado em Engenharia Eletrônica pela PUCRio; Graduado em Psicologia pela UFSC; Mestre em Engenharia de Produção e Ergonomia, UFSC. Doutor em Engenharia de Produção, UFSC. 